\title{
The Formation Mechanism of Porosity for Spray-deposited 7075 Alloy
}

\author{
Fuyang Cao ${ }^{a}$, Haichao Li $^{a}$, Zhiliang Ning", Yandong Jia ${ }^{a}$, Xu Gu ${ }^{a}$, Lei Yu ${ }^{a}$, Zuyan Liu ${ }^{a}$, Jianfei Sun ${ }^{a}$ \\ ${ }^{a}$ School of Materials Science and Engineering, Harbin Institute of Technology, \\ Harbin 150001, People's Republic of China
}

Received: September 11, 2014; Revised: September 22, 2015

\begin{abstract}
The distribution model of temperature for the billets was established based on the porosity formation mechanism. By calculating the numerical relationship between the temperature of the deposition layer and the formation ability of the porosity, the distribution of porosity for spray formed 7075 aluminum billets was predicted and the influence of superheat on the formation probability of porosity was analyzed. The results show that a denser billet can be obtained with the average temperature of $813 \mathrm{~K}$ of the droplets and a liquid fraction of $50 \%$. The porosity would increase whether the temperature further increased or decreased. Finally, the 7075 aluminum alloy was prepared by spray deposition technique with the optimum process parameters. It can be found that the distribution and types of the porosity were different at different locations. These results are in good agreement with the porosity distribution law.
\end{abstract}

Keywords: spray deposition, superheat, porosity distribution, formation mechanism

\section{Introduction}

In recent decades, spray forming has become an important technology in the field of metallurgical materials ${ }^{1-3}$. Combination of atomization and deposition makes it possible for preparing high-performance materials and near-net shape billets with minimal steps. However, the presence of some porosity is inevitable in spray formed materials, which brings extremely negative impact on material properties, especially for ductility and toughness ${ }^{4,5}$. In order to eliminate porosity defects, secondary processes, such as extrusion, rolling, hot isostatic pressing and forging, are necessary for achieving full densification.

The formation of porosity during spray forming is a complex process and controlled by a series of processing parameters, such as metal superheat, gas-liquid ratio, spray distance, as well as the growth and heat transfer model of the deposition billets ${ }^{6-9}$. The influences of these parameters on porosity must be further studied in order to obtain the billets with high relative density. Accordingly, in this article, a porosity model is proposed based on the analysis of the movement and heat transfer of droplets, particle packing theory and fluid mechanics at the surface of the deposition layer. By using this model, the formation and distribution laws of porosity for sprayed aluminum alloy have been investigated and the influence of temperature on porosity has been analyzed. Based on this, the applicability of the model was assessed through a porosity detection of spray formed 7075 alloy which was produced with pre-set processing parameters.

\section{Model Description}

The porosity in billets can be divided into three types according to different formation mechanisms: gas porosity, interstitial porosity, and solidification porosity ${ }^{10,11}$. The formation

*e-mail: jfsun_hit@263.net,jfsun@hit.edu.cn schematic view of gas porosity is shown in Figure 1a. This type of porosity is often presented in materials with large size and rounded morphology. It is formed due to the presence of relatively excessive amount of liquid phase of the billet. When a particle with very high speed impacting directly into the deposited layer, a channel will be form and subsequently covered by following particles. Figure $1 \mathrm{~b}$ shows the formation schematic view of interstitial porosity. As particles reached at the deposited layer which contain a large amount of solid, these particles can not completely spread out, thus leading to the accumulation of interstices. In the subsequent solidification process, these interstices can not be completely filled by liquid and result in the formation of interstitial porosity. The third type of porosity is formed due to the solidification shrinkage. Since it usually exists together with gas porosity and it is difficult to distinguish from each other, both of them are treated as one single porosity source.

The adhesion and spreading of the droplets during deposition process are depending on the solidification status of the arriving droplets and the deposition layer ${ }^{12}$, as is shown in Table 1. Billets with high density can be obtained when the arriving droplets and the deposition layers are all within a certain range of solid-liquid phase ratio. Conversely, an excess of solid or liquid phase will reduces the density of the deposited layer. Therefore, in order to obtain a dense billet, the liquid fraction of the deposited layer should be maintained within the range from 20 to $50 \%$, while the liquid fraction of the droplets should also be between 40 and $60 \%$.

The solidification status of the arriving droplets and the deposition layer are mainly influenced by the temperature of the arriving droplets and the heat transfer condition of the billet. In a long spray forming process, the heat transport of the billet will be in equilibrium, so the temperature and the 


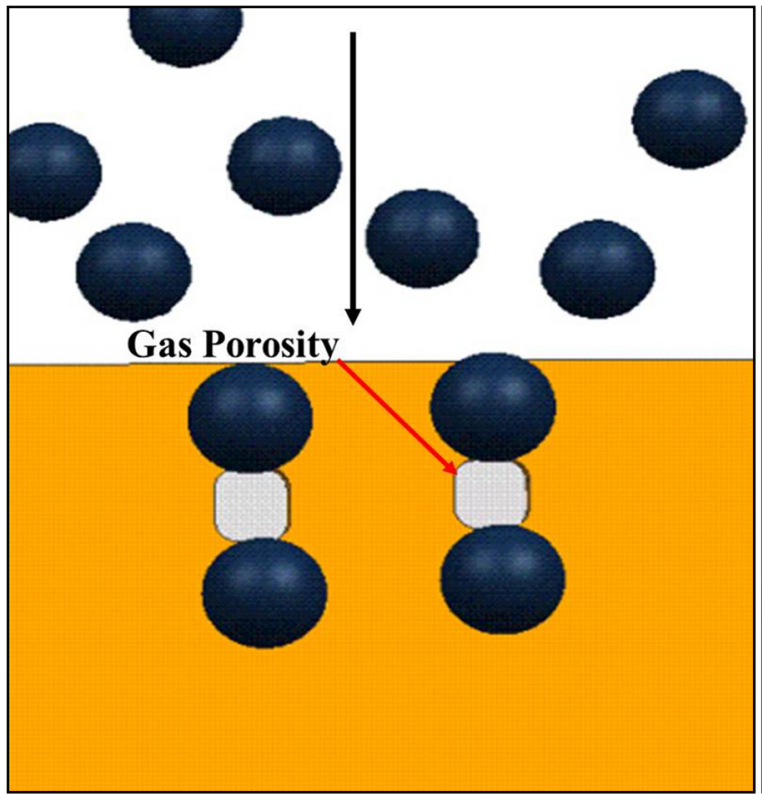

(a)

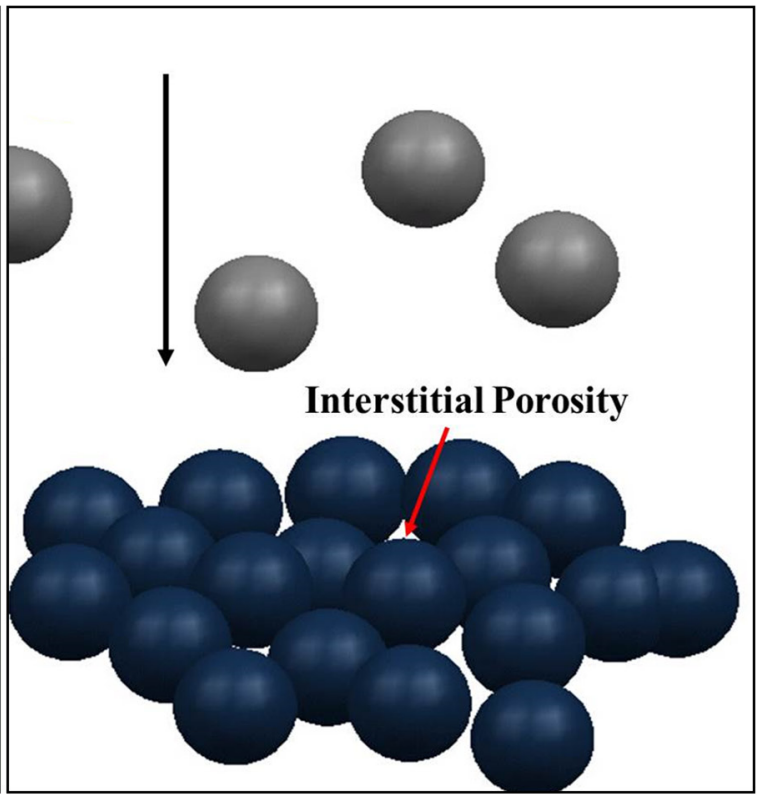

(b)

Figure 1. Porosity formation schematics of sprayed billets (a) Gas porosity; (b) Interstitial porosity.

Table 1. The deposition effect influenced by the status of droplets and deposition layer.

\begin{tabular}{|c|c|c|c|c|}
\hline 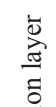 & $\mathrm{L}$ & $\begin{array}{c}\text { surface } \\
\text { splashing } \\
\text { (Low viscosity) }\end{array}$ & $\begin{array}{c}\text { surface } \\
\text { splashing } \\
\text { (Low viscosity) }\end{array}$ & $\begin{array}{c}\text { surface } \\
\text { splashing } \\
\text { (Low viscosity) }\end{array}$ \\
\hline 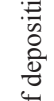 & M & $\begin{array}{l}\text { Parts of solid } \\
\text { particles } \\
\text { rebounding }\end{array}$ & \multicolumn{2}{|c|}{ Good bonding } \\
\hline 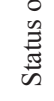 & S & $\begin{array}{l}\text { All of solid } \\
\text { particles } \\
\text { rebounding }\end{array}$ & Part of bonding & $\begin{array}{l}\text { Coating } \\
\text { structure }\end{array}$ \\
\hline & & $\mathrm{S}$ & M & $\mathrm{L}$ \\
\hline & & \multicolumn{3}{|c|}{ Status of droplets } \\
\hline
\end{tabular}

S—solid, M-semisolid, L-liquid.

solid-liquid phase ratio of the arriving droplets ultimately affect the status of the deposition layer. The movement and heat transfer of droplets in the spray cone are controlled by the high speed atomization gas. In order to figure out the average solid fraction of the arriving droplets under different process parameters, droplet dynamics and thermal model in-flight process were established.

Once a droplet detached from the atomizer, the speed difference between the droplet and the atomizing gas will result in a drag force which leads to the droplet acceleration. Until the speed of the droplet exceeds the gas, it starts to slow down. Equation of the droplets motion can be expressed as follows ${ }^{13}$ :

$\frac{d v d}{d t}=\frac{3}{4} \frac{C D \rho d}{d \rho g}(v g-v d)|v g-v d|+g\left(1-\frac{\rho g}{\rho d}\right)$

where $\rho_{\mathrm{d}}$ is the density of droplets, $C_{\mathrm{D}}$ is the drag coefficient of gas to droplets. This equation assumes that the droplets motion is only affected by gravity and the adjacent fluid drag.
During the atomization process, the temperature of the droplets is much higher than surroundings, witch will lead to intense heat exchange between the droplets and atomization gas. The heat exchange process is mainly dominated by convection heat transfer since the volume of the droplets is extremely small. Along with the temperature decreasing, the droplets gradually solidify and release latent heat. The heat balance equation can be expressed as follows ${ }^{14}$ :

$\rho C_{p} \frac{d T}{d t} V_{k}=h(T g-T) A k+\rho H f \frac{d f_{s}}{d t} V_{k}$

By using the mathematical model above, the velocity and temperature distribution of the droplets of 7075 alloy are calculated and the average solid fraction of the droplets can be obtained.

Figure $2 \mathrm{a}$ and $2 \mathrm{~b}$ show the relationships among the initial temperature of liquid metal, spray distance and solid fraction. The solid fraction is zero when the flying distance is less than a certain value, then it increases with flying distance increasing until the droplet completely solidified. Figure $2 \mathrm{c}$ is the planar projection view, from which the influence of superheat and spray distance on solid fraction can be clearly seen. Line 1 in the figure shows the solid fraction of $50 \%$.

During the flying process, the convective heat transfer coefficient of droplets of different sizes can be calculated, and the temperature change can be further calculated by analyzing the transfer conditions of the droplets. The temperature change curves with different sizes of droplets are shown in Figure 3, in which the temperature of the liquid metal is $1048 \mathrm{~K}$. It can be seen that the larger the droplet size, the lower the cooling rate is. The solid fraction of the droplets at different spray distances can be confirmed by the cooling curves. For smaller droplets, they would completely become solid particles after a short distance of flying, however, when the diameters of the droplets are greater than $200 \mu \mathrm{m}$, they 


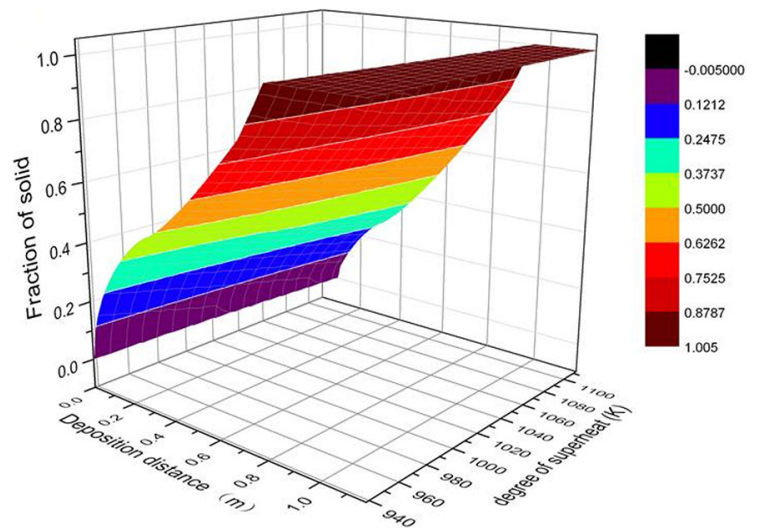

(a)

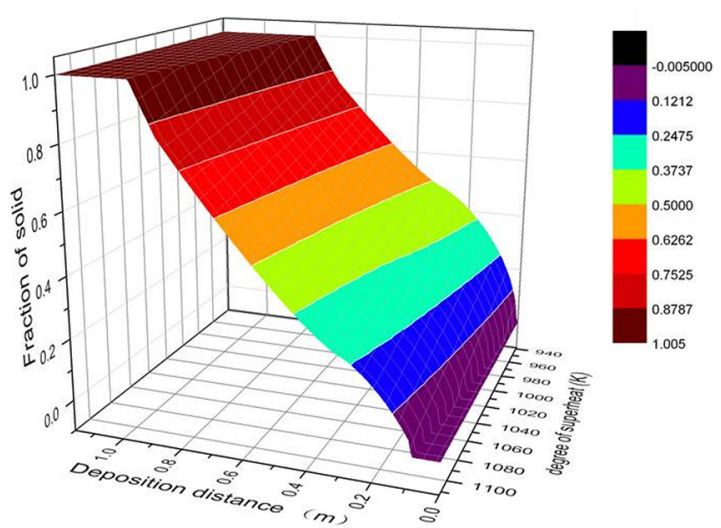

(b)

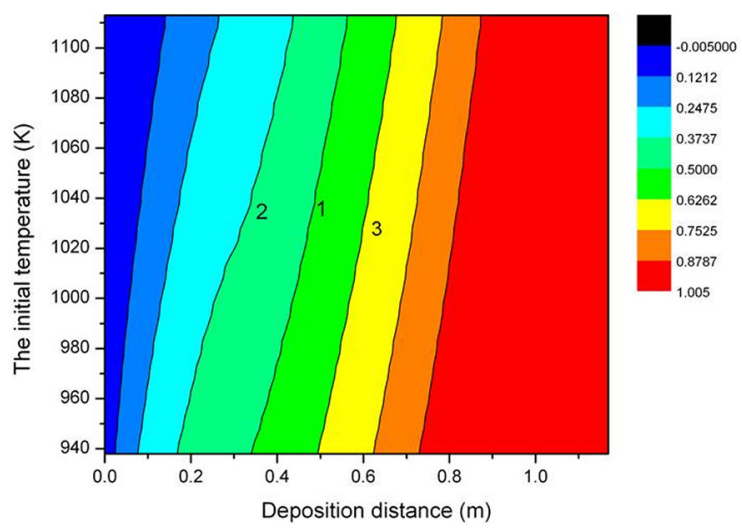

(c)

Figure 2. Relationships between initial spray temperature, spray distance and solid fraction (a); (b) Three dimensional stereogram; (c) Projection drawing.

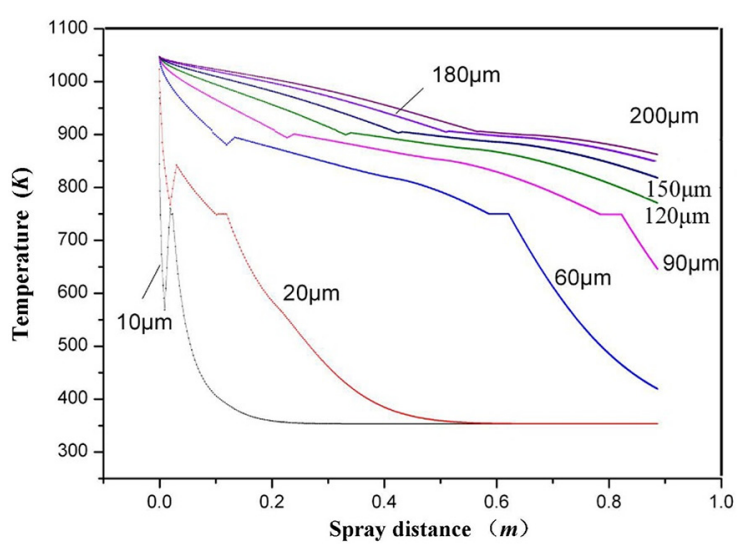

Figure 3. Temperature variation regularity during spray process.

remain liquid at the distance of $200 \mathrm{~mm}$ away from the atomizer. Under the condition of this study, the average size of the spray droplets is between 80 and $100 \mu \mathrm{m}$. At the spray distance of $500 \mathrm{~mm}$, the average temperature of the droplets is $813 \mathrm{~K}$, accomplished with the average solid fraction of about $50 \%$, which is suitable for the deposition of a dense billet. It can be calculated that when the temperature of the liquid metal increases $50 \mathrm{~K}$, which reaches $1098 \mathrm{~K}$, the temperature of the droplets at the distance of $500 \mathrm{~mm}$ is about $823 \mathrm{~K}$, and the average solid fraction is about $45 \%$.

According to the porosity formation mechanism mentioned previously, the formation of porosity has a direct relationship with the temperature of deposition layer. A lower temperature of the deposition layer will lead to the formation of interstitial porosity, while a higher temperature of the deposition layer may cause gas porosity and solidification porosity. Therefore the spread effect of droplets on the deposition layer is very important for the purpose of obtaining a dense structure. The spread ability of the droplet is related to its viscosity according to the rheological theory. The viscosity of the droplet is proportional to the liquid fraction of $-5 / 2$ power, and same for the temperature. In the deposition process, there exists a temperature range in which the droplets can be spread out with strong ability to make sure the deposition layer has a sufficient strength to maintain its shape. Through experiments, we can find that with liquid fraction of $50 \%$, the impact deformation rate of a spherical droplet can reach $300 \%$, while at the same condition of liquid fraction, the viscosity of the deposited layer is equivalent to seven times of the pure liquid metal. When droplets impact on the deposition layer, the deformation of the layer is small and will not form pits. If the deposition layer exceeds the temperature at which the liquid fraction of $50 \%$, the viscosity of the deposition layer decreases with a rate of 2.5 power to the temperature 
increase, and porosity will increase at the same rate. If the deposition layer is lower than this temperature, the time for spreading out becomes shorter since the deposition layer has a cooling effect on the droplets. For the case of the deposited layer temperature decreases, the porosity increase rate can be approximately inversely proportional to the temperature change.

According to the experience and analysis above, the porosity model is established based on the temperature difference between the droplets and the deposition layer in different deposition stages. The empirical equation of porosity formation in spray forming billets can be expressed as:

$Q_{x}= \begin{cases}A 1+B 1(T b-T d)^{C_{1}} & T b>T d \\ A 2+B 2(T d-T b)^{C_{2}} & T d>T b>T e \\ A 3+B 3(T e-T b)^{C 3} & T b<T e\end{cases}$

where $T_{B}$ is the temperature of the deposition layer, $T_{D}$ is the temperature of the droplets with liquid fraction of $50 \%, T_{E}$ is the eutectic temperature of the alloy. From the foregoing, it can be known that the value of $\mathrm{C}_{1}$ is 2.5 . Other values are repeatedly modified by experiments, and the suitable experience values are shown as follows:

$\mathrm{A} 1=\mathrm{A} 2=0, \mathrm{~B} 1=\mathrm{B} 2=\mathrm{B} 3=1 / 10000$,

$\mathrm{A} 3=0.0289, \mathrm{C} 2=2, \mathrm{C} 3=1.1$

By using this model, the porosity distribution can be simulated and quantitatively calculated.

\section{Results and Discussion}

The shape model of spray formed billets was established by tracing surface coordinates of the billets, and the temperature distribution model of the billets was further established by coupling the heat transfer model with shape model. The porosity formation probability of different regions for the billets could be predicted based on the numerical relationship between the temperature of the deposition layer and the porosity forming probability. For easy comparison, this study fixed the spray distance $(500 \mathrm{~mm})$, atomization pressure $(1.2 \mathrm{MPa})$ and catheter diameter $(4.0 \mathrm{~mm})$ as constant, the temperature of the liquid metal as variable.

Figure 4a shows the shape and the temperature distribution of the billet at atomization temperature of $1048 \mathrm{~K}$. It can be seen that there exists a large solid-liquid mixing area at the deposition layer of the billet, in which the temperature is evenly distributed between $773 \sim 783 \mathrm{~K}$ and close to the temperature of droplets. Therefore, interstitial porosity could not form due to the rapid solidification of the droplets. Meanwhile, the solid fraction of this area is about $57 \%$, with a sufficient strength and no significant deformation can be found under the impaction of the droplets.

The prediction of porosity distribution of the billet under this process conditions is shown in Figure 4b. The deeper the color, the greater the porosity forming probability is. From the curve of the scan line, it can be seen that the porosity is more than $10 \%$ at the bottom of the billet, and then the porosity decreases rapidly with deposition continuous. When the height of the billet is more than $50 \mathrm{~mm}$, the porosity remains the same magnitude of $\sim 1 \%$, and at the edges of the upper areas, the porosity increases to $2 \% \sim 3 \%$. The porosity distribution law can be analyzed as follows: In the area of the bottom of the billet where contacted with the deposition apparatus, large shrinkage porosity can be formed when droplets impacting the cold deposition layer and rapidly solidifying with short time to spread out. As deposition continuous, the temperature of the deposition layer increases and gradually stabilizes, thus making the porosity decreases to only about $1 \%$. In the edge of the billet, the porosity will increase slightly due to the longer flying distance of the droplets and lower temperature of the deposition layer.

Figure 5a shows the porosity distribution at the spray temperature of $1133 \mathrm{~K}$. Under this condition, the superheat of the liquid metal is $225 \mathrm{~K}$, and the temperature of the deposition layer is about $817 \mathrm{~K}$ with the liquid fraction of about $52 \%$. Thus the strength of the deposition layer decreases, and gas porosity will be generated in the middle area. The final porosity is about $2 \sim 3 \%$. Compared with Figure $4 b$, the high porosity area in the initial stage of the billet is slightly smaller, which indicates that the deposition process is entered faster into stable stage.

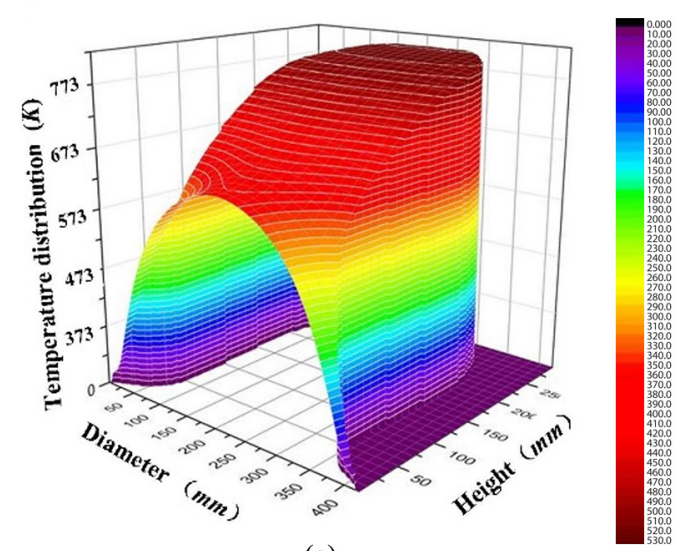

(a)

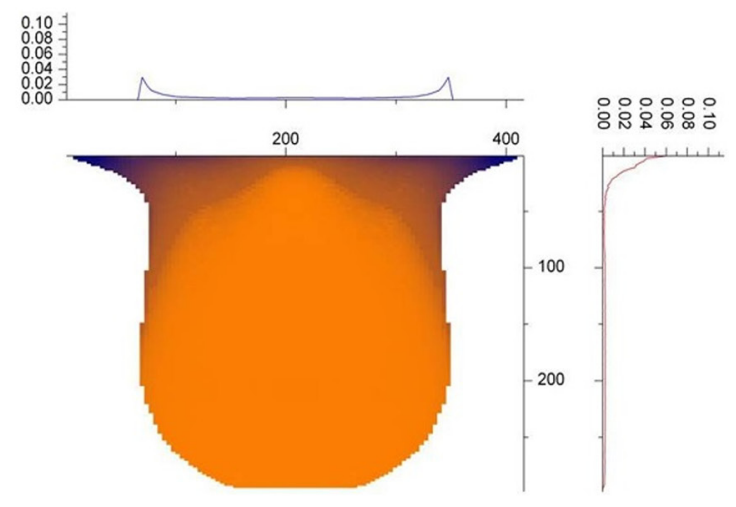

(b)

Figure 4. (a) The contour of the billet and the temperature distribution at longitudinal section; (b) Porosity distribution of billet at the spray temperature of $1048 \mathrm{~K}$. 
Figure 5b shows the porosity distribution at the spray temperature of $938 \mathrm{~K}$. Under this condition, the superheat temperature of the liquid metal is $30 \mathrm{~K}$, and the temperature of the deposited layer is about $754 \mathrm{~K}$ with the liquid fraction of about $19 \%$. The deformation ability of the droplets is so weak that it influences the spreading out of droplets. As seen from the figure that the porosity of the billet is as high as about $3 \%$ and the porosity type is interstitial porosity.

Through the research findings above, conclusions can be gotten that the selectable sprayed temperature range of 7075 aluminum alloy is narrow. A denser billet can obtained only when the superheat is among $120 \sim 190 \mathrm{~K}$. At the initial stage of the spray forming process, more porosity is generated and then gradually decreases in stable growth stage.
To validate the porosity model, a 7075 aluminum billet was prepared by spray forming process with the spray temperature of $1048 \mathrm{~K}$. A slice with thickness of $10 \mathrm{~mm}$ was taken in the central portion of the billet and 9 samples were taken at different positions of the slice in the order of 1-9 (Figure 6a). Microstructural observations of the alloy were carried out by using an Olympus optical microscope (OM) after etching with Keller's reagent $(1 \% \mathrm{HF}, 1.5 \% \mathrm{HCl}$, $2.5 \% \mathrm{HNO}_{3}, 95 \% \mathrm{H}_{2} \mathrm{O}$, vol. \%).

The porosity of the nine parts is shown in Figure $6 \mathrm{~b}$, the order of the metallographic pictures is consistent with the sampling sequence in Figure 6a. As can be seen from the pictures that the porosity of the upper areas of the billet is significantly less than the bottom areas, which presents the

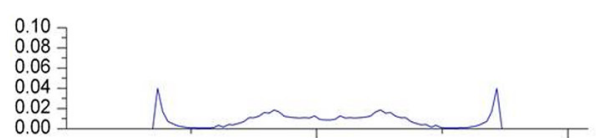

0.001

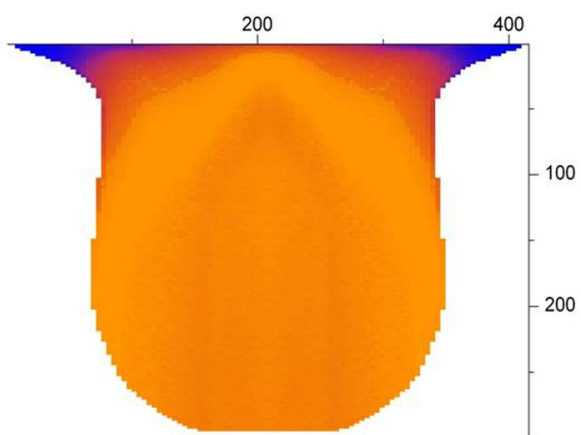

(a)

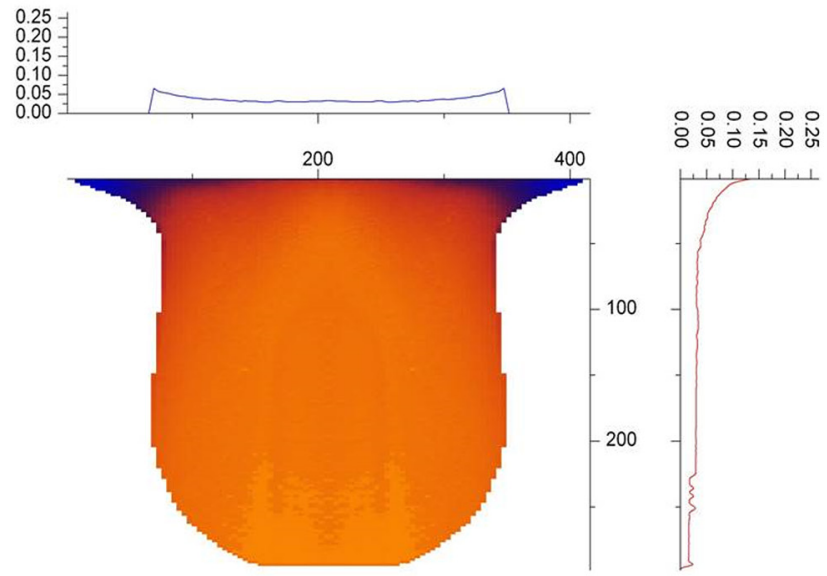

(b)

Figure 5. Porosity distribution of billets at different spray temperature (a) $1133 \mathrm{~K}$; (b) $938 \mathrm{~K}$.

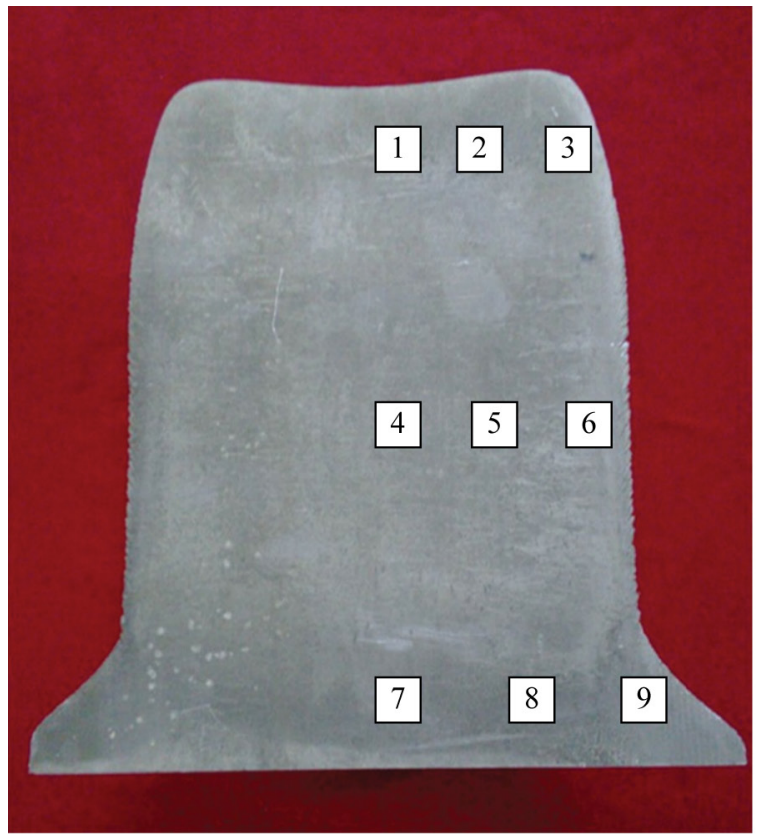

(a)
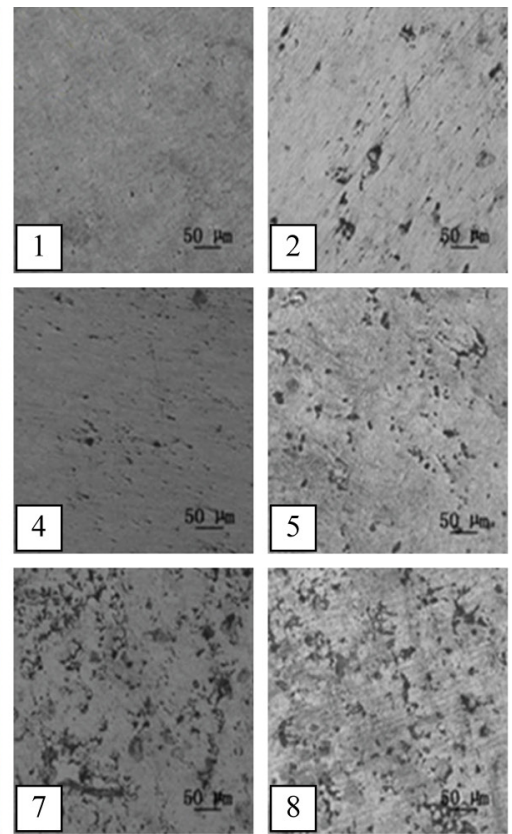

(b)
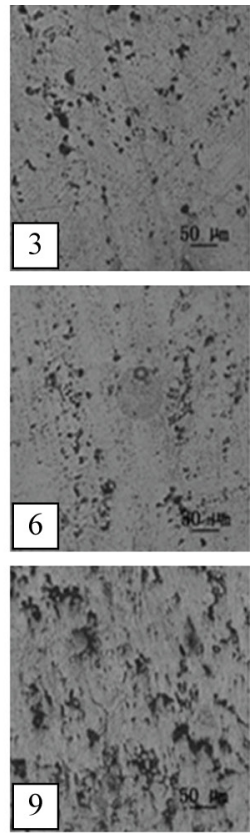

Figure 6. Porosity observation of sprayed 7075 billet (a) Sampling locations; (b) Metallographic observation. 


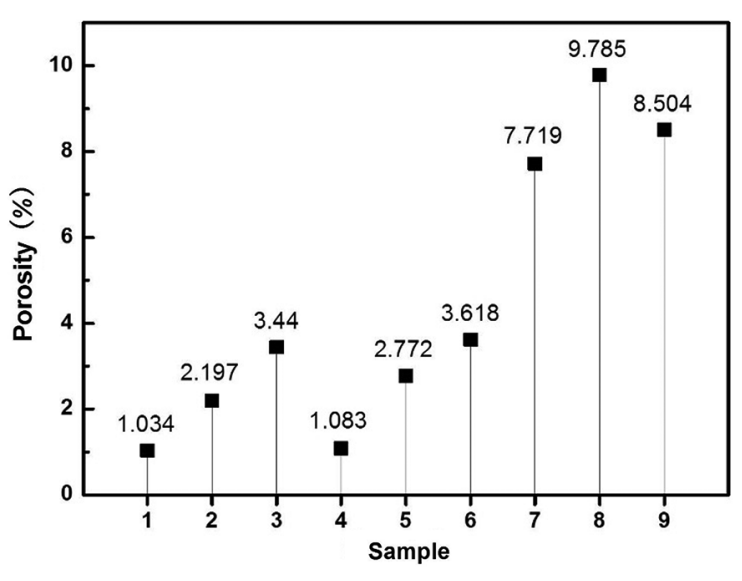

Figure 7. The vertical map of porosity distribution.

regularity of increasing from top to bottom, center to edges. Image-pro plus software of measurement and analysis was used to calibrate the porosity in the metallographic pictures. Each sample was measured in four different positions, and the average porosity rate is shown in Figure 7. These experiment results above are basically consistent with the porosity distribution law obtained by the numerical simulation,

\section{References}

1. Yang B, Wang F and Zhang JS. Microstructural characterization of in situ TiC/Al and TiC/Al-20Si-5Fe-3Cu-1Mg composites prepared by spray deposition. Acta Materialia. 2003; 51(17):49774989. http://dx.doi.org/10.1016/S1359-6454(03)00292-1.

2. Grant PS. Spray forming. Progress in Materials Science. 1995; 39(4-5):497-545. http://dx.doi.org/10.1016/0079-6425(95)00004-6.

3. Lavernia EJ and Delplanqueb J-P. Spray casting: applications. Encyclopedia of Materials: Science and Technology. 2001;87718775. http://dx.doi.org/10.1016/B0-08-043152-6/01572-2.

4. Bergmann D and Fritsching U. Sequential thermal modelling of the spray-forming process. International Journal of Thermal Sciences. 2004; 43(4):403-415. http://dx.doi.org/10.1016/j. ijthermalsci.2003.10.004.

5. Frigaard IA and Scherzer O. Spraying the perfect billet. SIAM Journal on Applied Mathematics. 1997; 57(3):649-682. http:// dx.doi.org/10.1137/S0036139995287132.

6. Bergmann D, Fritsching U and Bauckhage K. A mathematical model for cooling and rapid solidification of molten metal droplets. International Journal of Thermal Sciences. 2000; 39(1):53-62. http://dx.doi.org/10.1016/S1290-0729(00)00195-1.

7. Pryds NH, Hattel JH, Pedersen TB and Thorborg J. An integrated numerical model of the spray forming process. Acta Materialia. 2002; 50(16):4075-4091. http://dx.doi.org/10.1016/S13596454(02)00205-7. which illustrate that the established porosity fuzzy model is reasonable and suitable for the simulation and calculation of aluminum alloys in spray forming process.

\section{Conclusion}

In this research, numerical simulation methods have been used to investigate the porosity forming and distribution mechanism of sprayed aluminum alloys. It is found that the status of solidification for the arriving droplets and the deposition layer is the key factor in determining the porosity formation. Under the same condition, even a higher or lower spray temperature will lead to the increasing of different types of porosity. For sprayed 7075 alloy, a denser billet can be obtained with the spray temperature of $1048 \mathrm{~K}$. In this condition, the porosity of the billet presents the regularity of increasing from top to bottom. At the bottom of the billet, the porosity type is mainly solidification shrinkage porosity of about $10 \%$, and at the upper area,the porosity is about $1 \%$ or less with mixed types.

\section{Acknowledgements}

This project is supported by National Natural Science Foundation of China (Grant No. 51375110), and the National 973 Plan Project of China (Grant No. 2010CB631205).

8. Zeoli N and Gu S. Numerical modelling of droplet break-up for gas atomisation. Computational Materials Science. 2006; 38(2):282-292. http://dx.doi.org/10.1016/j.commatsci.2006.02.012.

9. Mates SP and Settles GS. Numerical modelling of droplet breakup for gas atomisation. Computational Materials Science. 2005; 15:19-40. http://dx.doi.org/10.1016/j.commatsci.2006.02.012.

10. Fukanuma H. A porosity formation and flattening model of an impinging molten particle in thermal spray coatings. Journal of Thermal Spray Technology. 1994; 3(1):33-43. http://dx.doi. org/10.1007/BF02648997.

11. Cai WD and Lavernia EJ. Modeling of porosity during spray forming. Materials Science and Engineering A. 1997; 226228:8-12. http://dx.doi.org/10.1016/S0921-5093(96)10580-3.

12. Mathur P, Annavarapu S, Apelian D and Lawley A. Spray casting: an integral model for process understanding and control. Materials Science and Engineering A. 1991; 142(2):261-276. http://dx.doi.org/10.1016/0921-5093(91)90665-A.

13. Xue M, Heichal Y, Chandra S and Mostaghimi J. Modeling the impact of a molten metal droplet on a solid surface using variable interfacial thermal contact resistance. Journal of Materials Science. 2007; 42(1):9-18. http://dx.doi.org/10.1007/ s10853-006-1129-x. PMid:17200810.

14. Grant PS. Solidification in spray forming. Metallurgical and Materials Transactions. A, Physical Metallurgy and Materials Science. 2007; 38A(7):1520-1529. http://dx.doi.org/10.1007/ s11661-006-9015-3. 